\title{
Traumatic injury in Australia and New Zealand
}

\author{
Kate Curtis, RN, PhD a,b,c,d,e Erica Caldwell, RN, BA, RM, Psych Cert ${ }^{f}$, \\ Andrea Delprado, RN, Grad Cert Bioethics s, h,i, Belinda Munroe, RN, MN ${ }^{a, b, d, *}$
}

\author{
a St George Hospital Trauma Service, Australia \\ b Sydney Nursing School, University of Sydney, Australia \\ c The George Institute for Global Health, Australia \\ dEmergency Department, The Wollongong Hospital, Australia \\ e St George Clinical School, Faculty of Medicine, University of NSW, Australia \\ f Trauma Department, Liverpool Hospital, NSW, Australia \\ s CareFlight International Air Ambulance, Australia

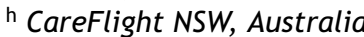 \\ ' Australasian Trauma Society, Australia
}

Received 20 July 2011; received in revised form 1 December 2011; accepted 1 December 2011

\section{KEYWORDS}

Trauma;

Epidemiology;

Australia;

New Zealand;

Patient outcomes;

Suicide
Summary Injury is a leading cause of mortality, hospitalised morbidity and disability in Australia and New Zealand. Of the many public health challenges facing clinicians on a daily basis, traumatic injury is one of the most significant. A large spectrum of injury severity may result, ranging from minor injuries which require little medical intervention through to severe multisystem trauma, requiring definitive management by an experienced multidisciplinary team. An improved understanding of the incidence and prevalence of trauma can empower clinicians of all levels of experience to contribute to improving the trauma system they work in at a local level. This paper provides an overview of the history and epidemiology of traumatic injury in Australia and New Zealand. The reading of this article and completion of revision questions is equivalent to $2 \mathrm{~h}$ of self-directed learning.

(c) 2011 College of Emergency Nursing Australasia Ltd. Published by Elsevier Ltd. All rights reserved.

\footnotetext{
* Corresponding author at: Trauma Services, St George Public Hospital, Gray St, Kogarah 2217, New South Wales, Australia.

Tel.: +612 91132686, fax: +61291133974.

E-mail address: belinda.munroe@sesiahs.health.nsw.gov.au (B. Munroe).
}

\section{Introduction}

Trauma as a cause of mortality and morbidity on a global scale is increasing, whether from large-scale disasters (both natural and man-made) or the day-to-day non-intentional injuries and intentional interpersonal violence. In 2000, injuries accounted for $11 \%$ of global mortality and $13 \%$ of all disability-adjusted life-years. ${ }^{1}$ By 2030 , road traffic injuries are expected to become the fifth leading cause of death and 
the third leading cause of disability worldwide, with about $90 \%$ of this burden occurring in low- and middle-income countries, costing US\$ 518 billion globally. ${ }^{1}$ In Australia and New Zealand injury is a leading cause of mortality and hospitalised morbidity.

In view of the magnitude of this problem, the role of trauma clinicians is pivotal. Trauma clinicians require not only an in-depth understanding of the mechanism of injury, physiological responses to trauma and structured approaches to trauma management; they also need to understand the determinants and extent of traumatic injury as a significant and burgeoning public health issue. As well as a working knowledge of trauma systems, their role within these systems and an understanding of how this role can optimize patient outcomes through the continuum of trauma care.

This article is intended to expand clinicians understanding of the impact traumatic injury has in Australia and New Zealand. Revision questions are provided to test the reader's knowledge. Completion of the article and revision questions is equivalent to $2 \mathrm{~h}$ of self-directed learning.

\section{History}

In Australia and New Zealand, death and disability resulting from trauma is embedded in the evolution of these societies. Death and injury resulting from falls or tribal conflict and as sequelae of nomadic life are an integral part of Indigenous Australian Aboriginal Dreamtime. ${ }^{2}$ During European colonisation of Australia and New Zealand, traumatic injury was a common cause of death among convicts and settlers alike. ${ }^{3}$ Indeed, trauma was once considered an inevitable part of life in terms of how often it occurred and how likely it was to result in death. However, present-day expectations of trauma management and injury outcomes have changed substantially.

Contemporary understanding of patterns of injury and physiological responses to trauma were accelerated through periods of military conflict. During World War II countless lives were saved through the simple actions of splinting and immobilisation of major fractures. ${ }^{4}$ The Vietnam War saw a significant improvement in our understanding of the physiology of shock ${ }^{4}$-the importance of haemostasis and fluid resuscitation resulted in the emergence of surgical field hospitals. Consequently, soldiers were surviving long enough to return home to contend with permanent physical disabilities and post-traumatic stress that resulted from their injuries.

Despite this improved understanding, trauma remains the leading cause of death in women and men under the age of 45 years in both Australia and New Zealand. ${ }^{5-7}$ In Australia, injury was first recognised as a national health priority in 1986. ${ }^{8}$ Despite the acknowledged importance of injury as an issue, and injury prevention as a solution, progress towards a systematic response has been slow.

Epidemiology acts as an essential instrument in understanding trauma as both a clinical and a public health problem because of its implications for clinical practice, social policy, public policy, legislation, injury prevention programs and as a source of data for trauma research. Data elements such as incidence, prevalence, rates, risk, age, sex, ethnicity, geographical distribution, morbidity and mortality are rich sources of information for both clinicians and public health researchers alike. The establishment of a bi-national approach to data collection across the last decade took shape in the form of the National Trauma Registry Consortium (Australia and New Zealand) and contributed to a collaboration of national data collection and reporting on patients sustaining serious injury $($ ISS $>15) .{ }^{9}$ At the time of publication, bi-national data collection and reporting was on hold due to a lack of sustained funding. However, in November 2010 the Alfred Hospital/National Trauma Research Institute in Melbourne and the National Critical Care and Trauma Response Centre in Darwin announced an agreement to jointly fund the further development of the Australian National Trauma Registry by contributing $\$ A 350,000$ each over the next two years. ${ }^{10}$ Efforts to obtain federal government support for this important program continue.

\section{The burden of injury}

The cost to society as a result of trauma is significant, impacting both economic expenditure and individual quality of life. In order to understand the scale of trauma as a public health problem, consideration of the prevalence and types of trauma alone is insufficient. The effect of injury on society must too be considered in order to monitor its impact on acute health and rehabilitation services, the workforce, and patient's families and significant others. Ongoing measurement of the impact of trauma in these areas is necessary to guide clinicians, from pre-hospital to rehabilitation; and inform public policy, legislation, funding, resource allocation and distribution.

\section{Economic cost}

The burden injury has on economic consumption is documented in different ways depending on mechanism of injury. Road injury costs include property damage, long-term disability costs and insurance administration costs in a full-cost model. Work-related-injury costing models include time off work, lost production, equipment damage cost, compensation costs and insurance administration costs. Traumatic injury accounts for a significant number of hospital admissions which accounts for a considerable portion of trauma related expenditure. Outside these areas, cost of injury data is limited, making comparisons difficult.

In 2004-05, injury accounted for \$A3.4 billion of allocated health expenditure in Australia-an increase of $22 \%$ since 2001-the greatest proportion of which was spent during hospital admission. ${ }^{11}$ In 2008-09, Australia-wide, trauma was responsible for 522,330 hospitalisations, the second highest cause of hospital admissions expenditure, following cardiovascular disease. ${ }^{11}$ In 2007-2008, there were 902,000 separations (or admissions) which reported an external cause, and these separations accounted for 6.3 million patient days. ${ }^{12}$ This represented $11.5 \%$ of all separations and $24.5 \%$ of all patient days. When removing separations by poisoning and complications of medical/surgical care, this number is reduced to $464,000(5.8 \%)$ and 2,645,682 (10.3\%). The majority of separations and patient days were reported for the public sector. 
In New Zealand, injury (unintentional and intentional) is the leading cause of death for ages 1-34 years, and the second leading cause of hospitalisation. Injuries account for more potential years of life lost than cancer and heart disease combined. In childhood, injury accounts for approximately $60 \%$ of all deaths; and by adolescence and young adulthood, injury (including suicide) accounts for approximately $80 \%$ of deaths. ${ }^{13}$ In 2008 the social and economic costs of injury were estimated to be at least \$NZ6-7 billion per year. ${ }^{14}$ Early research suggests that higher costs are associated with severity of injury and length of stay ${ }^{15}$; however, the complex nature of the trauma patient does not allow accurate funding prediction using the episode funding models currently employed in Australia.

\section{Human cost}

Human cost as a result of traumatic injury is vast, ranging from extensive recovery periods, long-standing disabilities and loss of life. For those who do not survive traumatic injury, there is a net loss of their contribution to society. ${ }^{1}$ On average, each fatal injury before the age of 75 years results in the loss of 32 years of potential life, compared with 9 years for cancer and 5 for cardiovascular disease. ${ }^{16}$ Injuries were responsible for $7.0 \%$ of the total burden of disease and injury in Australia in 2003, equating to 185,050 years of healthy life lost due to premature death or disability. ${ }^{17}$ The subsequent grief and loss experienced by families and significant others has an impact on their mental health, and leads to secondary healthcare costs, loss of productivity and subsequent economic burden.

For those who survive traumatic injury, recovery periods and long-term disabilities result in a reduced economic contribution and/or long-term economic liability imposed on health and social systems. Post Traumatic Stress Disorder (PTSD) and cognitive changes as a result of traumatic brain injury have been recognised as a significant cause of psychological impairment in response to injury. Some studies reporting an incidence of up to $51 \%$ of patients who had sustained traumatic injuries meeting diagnostic criteria for PTSD. ${ }^{18}$ Yet, psychological consequences such as PTSD are currently neglected in burden-of-injury calculations. ${ }^{19}$ While there is little evidence for the efficacy of early debriefing on post-traumatic injury, there is some evidence that early cognitive behavioural therapy may lessen the psychological impact of injury and help prevent progression to PTSD. ${ }^{20}$

\section{Patterns of injury}

Knowledge of the common mechanisms and patterns of injury are necessary to predict, treat and prevent traumatic injury. The severity and body region injured is often dependent on the means of injury and are prognostic of patient survival and recovery. Mechanisms range from blunt, penetrating and burns, all of which are capable of causing severe external and internal organ damage. In Australia and New Zealand almost $90 \%$ of all major trauma is blunt, approximately $6 \%$ penetrating and $5 \%$ burns. ${ }^{21}$ Injures may be isolated or effect multiple regions including the head, neck, face, chest, abdomen, pelvis, extremities and spine.

\section{Blunt injuries}

Blunt injury are caused by acceleration, deceleration, compression or shearing forces either resulting in the body being crushed or impacted with another object, or the shifting of internal organs. ${ }^{22}$ The majority of blunt trauma is related to motor-vehicle collisions (34\%), motorbike collisions (8\%), cyclists (4\%) and other transport (11\%). ${ }^{21}$ There is also a significant amount of blunt injury related to falls (22\%). Most incidents occur on the street or highway (56\%) or at home (20\%). Blunt trauma is most commonly from non-intentional causes, with less than $5 \%$ related to assaults. ${ }^{21}$ More than half the patients who sustain blunt chest trauma have significant head injuries, more than one-third have significant thoracic injuries, and upper and lower extremity injuries are common. Serious abdominal injuries occur in about $15 \%$ of patients, so that the total number of patients requiring abdominal surgery in blunt trauma is relatively small. Although serious thoracic trauma is more frequent, most thoracic trauma does not require surgery. ${ }^{21}$

The provision of trauma care in Australia and NZ is multidisciplinary, from the composition of trauma teams to the heavy reliance on subspecialty surgical care. In Australian trauma centres, trauma or general surgeons take the role of primary admitting surgeon; however, the bulk of the operative management is performed by orthopaedic surgeons $(66 \%)$. The remainder of surgery is performed by plastic and maxillofacial (10\%), neurosurgery (10\%), cardiothoracics, vascular, ear-nose-throat and urology surgeons, in decreasing order. ${ }^{23}$

\section{Penetrating injuries}

Penetrating injuries are those that result in an object entering the body by piercing the skin, including firearm injuries, stab wounds and impalements. ${ }^{22}$ Australasian firearm-related injuries are low in comparison with the rest of the world. ${ }^{24-26}$ Stabbings are far more common than gunshot wounds. For example, firearms are used in $8 \%$ of assaults in New Zealand compared with $50 \%$ in the USA. ${ }^{27}$ In Australia, the incidence of firearm use is not increasing significantly despite the public belief that violent crime has increased. In 2009, a firearm was involved in $18 \%$ of reported attempted murders, $12 \%$ of murders and $7 \%$ of robbery offences. Similarly, knives were used in 3267 recorded offences (or 19\%). ${ }^{28}$

Penetrating injury incidence in Australia can be related to geographical location. For example, in NSW the rate of stabbing and firearm injury presenting to hospital has not increased in central Sydney over the past 10 years, ${ }^{25,26}$ but in south-western Sydney the number of abdominal stab victims seen has increased by $50 \%$ and there has been a threefold increase in the number of gunshot wounds. ${ }^{26}$ While public locations such as a street, bar or nightclub are the most common for assault, self-inflicted shootings or stabbings are more commonly sustained in the patient's home. Patients are overwhelmingly male in their second and third decades of life. The use of alcohol and other drugs, gang membership, unemployment and firearm ownership are often identified as patient characteristics in victims of penetrating trauma. ${ }^{26,29}$ 
Most penetrating injuries are minor, with only a small proportion of trauma admissions sustaining severe injury (ISS > 15): stabbing $2.1 \%$ and gunshot wound $<1 \% .9$ The most commonly affected body regions are the thorax and abdomen. A small number of serious head injuries relate to self-inflicted gunshot wounds. Penetrating injury with laceration to an artery was the most common cause of vascular trauma in New Zealand, and of those injuries, complications such as wound, lung, urinary tract and other infections contributed significantly to morbidity. ${ }^{30}$

\section{Specific mechanisms of serious injury}

\section{Land transport}

Land transport incidents accounted for $11.4 \%$ of all hospitalisations due to injury in 2006-2007, equating to 52,066 persons seriously injured, 232,290 patient days in hospital with a mean length of stay of 4.5 days. ${ }^{31}$ Of those seriously injured, $63 \%(32,777)$ were due to traffic collisions, while $26.2 \%(13,639)$ were due to non-traffic (off-road) events. For $10.7 \%$, location was not specified. For traffic (on-road) collisions, $49.5 \%$ of those seriously injured were car occupants, $22.3 \%$ were motorcyclists and $14.6 \%$ were pedestrians; while for non-traffic (off-road) accidents, $43.4 \%$ of those seriously injured were motorcyclists, $30.6 \%$ were pedal cyclists and only $9.5 \%$ were car occupants. ${ }^{31}$

\section{Railway trains}

For the five-years 2002/2003 to 2006/2007, 910 persons were seriously injured in Australia due to transport accidents involving a train, an average of 182 per year. ${ }^{32}$ Victoria (37.1\%), NSW (34.3\%) and Queensland (17.5\%) accounting for almost $90 \%$. On a population basis, age-standardised serious injury rates tend to be higher for those aged 70 or over. Rail users made up two-thirds (66\%) of all serious injury cases, most commonly occuring while boarding or alighting from trains. Non-rail users were most commonly pedestrians (14.8\%) and car occupants (12.5\%) injured in collision with trains. Mean length of stay in hospital was 8.1 days, more than twice the length of stay for non-rail-related injuries (4.0 days). However, the risk of serious injury, based on kilometres travelled, is more than 10 times as high for passengers travelling by car than for passengers travelling by train. ${ }^{32}$

\section{Railway disasters}

Major railway disasters are uncommon, but when they do occur, involve a number of fatalities and persons seriously injured. These incidents are widely reported in the media, such as the Granville train disaster in 1977 (83 fatalities), Glenbrook, NSW in 1999 (7 fatalities), Waterfall in 2003 (7 fatalities) and the level-crossing crash near Kerang in Victoria in 2007 (11 fatalities). The estimated cost of rail incidents that occurred in Australia in 1999 was \$A133 million, with rail-related suicides and attempted suicides costing an estimated $\$$ A53 million. ${ }^{32}$

\section{Level-crossing incidents}

For the five-year period 2002/2003 to 2006/2007, 253 persons were seriously injured in Australia due to a level-crossing incident, an average of 51 per year; Victoria (53\%), Queensland (19\%), South Australia (12.6\%) and NSW $(10.7 \%)$. On a population basis, age-standardised serious injury rates were highest among young adults (20-24 years of age). Most common circumstances involved car occupants (42.3\%) and pedestrians (29.6\%) injured in a collision with a train. Mean length of stay in hospital was 11.9 days, almost three times the length of stay for non-rail-related injuries (4.0 days). ${ }^{32}$

\section{Sport}

Exercise is important in promoting health and wellbeing. However, sport and recreation injuries are common and, although predominantly minor, lead to people giving up sport, for example, in 1995-1996, 20.7\% of males and $18.7 \%$ of females gave up sport because of injury. ${ }^{33}$ Only 1 in 10 injuries presenting to emergency are admitted, but these tend to be more severe and costly. ${ }^{34}$ In Australia in 2002-2003, 6.3\% of hospitalisations from external cause (injury or poisoning) were sport- and recreation-related. ${ }^{35}$ The most common sport and recreation activities resulting in an ED presentation were Australian rules football (22\%), followed by cycling $(14.7 \%)$, basketball $(8.8 \%)$, soccer $(6.4 \%)$, play equipment and netball (both 6\%) and skateboarding/inline skating (5.1\%). ${ }^{36}$ Fractures are the most common injury resulting in admission (52.8\%). ${ }^{34}$

\section{Football}

Several codes of football are played commonly in Australia and New Zealand. These include soccer, Australian rules, rugby league and rugby union. Participation shows strong regional differences, with Australian rules being played in Victoria and South Australia and rugby predominantly played in NSW and Queensland. While soccer is the most widely played sport in the world, in Australia it was sixth most popular in 2003. ${ }^{37}$ In Queensland, 15.3\% of football-injury-related presentations to emergency were due to rugby league, $14.3 \%$ to soccer, $4.5 \%$ rugby union, $3.7 \%$ Australian rules, $3.1 \%$ touch football and $21.3 \%$ football unspecified. The injuries occur as a result of falls, or striking or colliding with another person or with an object. ${ }^{38}$

\section{Bicycles}

Cycling was the fourth most popular sport in 2003 in terms of participation. ${ }^{34}$ It is more popular with males $(12.4 \%)$ than females $(6.5 \%)$. The majority $(81.1 \%)$ of hospitalisations occurred in males. Of hospitalisations, $47.6 \%$ were for people aged 0-14 years. Head injury was the most common reason for admission (26\%), followed by elbow and forearm injury $(22.4 \%) .{ }^{34}$ Three-quarters of cycling-related deaths were due to head injury and $>90 \%$ were caused by collisions with motor vehicles. ${ }^{39}$ It has been shown that cycle helmets are effective in reducing head injury. ${ }^{39-41}$ The incidence of serious bicycling injury continues to rise. In Victoria ${ }^{42}$ during the 5 years ending June 2006, there were 25,920 bicyclerelated ED presentations, 10,552 bicyclists were admitted to hospital, 298 bicycling injuries were classified as major trauma, and there were 47 bicycling fatalities. Most of those injured were males, aged less than 35 years, with roadrelated injuries. Accurate data on cycling participation, use 
of injury prevention strategies, and injury profiles will assist in reducing bicycle-related injury. ${ }^{42}$

\section{Burns}

Burns injuries can result from scalds, hot objects, chemical, fire and flames, sun or friction causing injury to the skin. ${ }^{43}$ Burns injuries, particularly in young children and older persons, was identified as one of the priority injury issues in Better Health Outcomes for Australians. ${ }^{44}$ One per cent of the population of Australia and New Zealand $(220,000)$ suffers from burns each year. ${ }^{45}$ Over the past 20 years, the survival rate for patients with a severe burn injury has improved dramatically. Early surgical intervention, skin substitutes, nutrition and advances in intensive care have improved the survival and outcomes for patients with burns to $>80 \%$ of total body surface area. In addition to considerable physical and psychological suffering, injuries from burns were estimated to cost the Australian community $\$ A 330$ million annually in 1996, this is likely to have since increased significantly. ${ }^{45}$ In Queensland, burns are a common reason for children under 5 years of age to present to an ED, currently accounting for $4 \%$ of all injury presentations in this age group. ${ }^{46}$ Burns in children in this age group made up the largest single group of burns victims (33\%) across all ages. ${ }^{46}$ The vast majority occurred at home $(89 \%)$ and in the kitchen (47\%). Trend estimates over the seven-year study period showed no evidence of decline.

\section{Spinal cord injury}

Spinal cord injury $(\mathrm{SCl})$ is injury to the spinal cord that results in loss of motor or sensory function ${ }^{47}$ and is a significant public health problem in Australia. Australia was the first country to implement a national population-based register for surveillance of $\mathrm{SCl}$ cases. ${ }^{48}$ The $\mathrm{SCl}$ population has been estimated to number in excess of 6000 , with ongoing costs associated with the long-term care estimated to be about \$A200 million per year.

In Australia in 2007-2008, the main causes of traumatic $\mathrm{SCl}$ were land transport involving motor vehicle occupants and unprotected road users, i.e. motor cyclists, pedal cyclists, pedestrians; high and then low falls. ${ }^{49}$ This was inversely the case in New Zealand from 2007 to 2009, where falls accounted for the highest percentage of $\mathrm{SCl}$, followed by medical causes such as spinal abscess, Guillian-Barré and metastatic lesions, then motor vehicle and then motorbike collisions. ${ }^{49,50}$

\section{Trauma mortality in Australia}

Injury is the fourth most common cause of death in Australia and accounts for more years of lost life up to 65 years of age than cardiovascular disease and cancer combined. ${ }^{51}$ The four most prevalent causes of injury death in Australia are suicide (30\%), transport accidents (24\%), falls (19\%) and assault (4\%). ${ }^{16}$ Prior to 1991 the leading cause of death from external causes was motor vehicle accidents, but after 1991 the death rate from road trauma became lower than the rate from suicide. It is important to recognise the limitations of

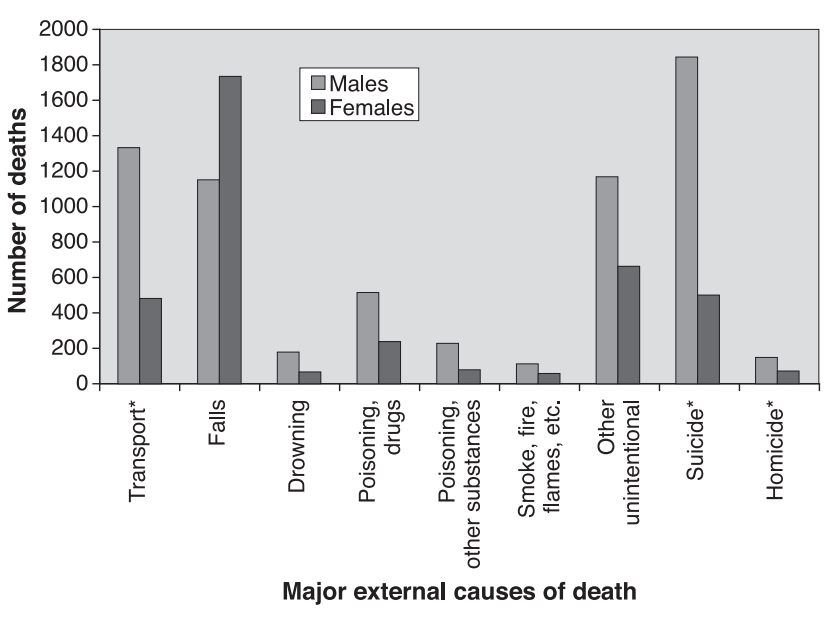

Figure 1 Major types of injury death, Australia 2004-2005. ${ }^{*}$ Counts based on estimates using National Coroners Information System; other counts based on Australian Bureau of Statistics data. Note that the sum of deaths in all categories exceeds the total number of community-injury deaths; this is because some cases had been assigned more than one external cause code and therefore may appear in more than one cause category.

Source: Curtis and Ramsden (Eds.) in Chapter 42, Overview of Trauma. Emergency and Trauma Care, August 2011, Elsevier. Original source-Figure 2.1.5 from Henley, G. and Harrison, J. (2009). Injury deaths, Australia 2004-05, Injury research and statistics series no. 51. AlHW cat. no. INJCAT 127. Canberra. ${ }^{51}$

the various data sources for injury mortality data. Information from several sources indicates that some estimates of numbers of injury deaths in 2004-2005, based on Australian Bureau of Statistics (ABS) mortality data, are falsely low. Comparisons between the number of deaths obtained using the ABS mortality unit record data collection and the number of deaths obtained using data supplied by the National Coroners Information System (NCIS) confirmed underestimation of motor vehicle traffic injury and homicide (Fig. 1). ${ }^{51}$

Rates of injury mortality are consistently higher in males than in females. The ratio between male and female rates in 2004-2005 was 2:1. ${ }^{51}$ Rates for both sexes were lowest in childhood and highest at ages 75 and older. Male rates were around 4-5 times higher than female rates at ages 20-34 years. People aged 75 years and older accounted for $38 \%$ $(n=3701)$ of all injury deaths, while young adults, in the age range 20-39 years, accounted for a further $24 \%(n=2343)$. Young males in this age range accounted for $19 \%$ of all injury cases. $^{51}$

Nationally, Australia's injury mortality rate is 46.7 deaths per 100,000 population. ${ }^{51}$ Across the states and territories, there are considerable differences in population-adjusted death rates. Rates were highest for the Northern Territory and Tasmania, which had age-adjusted rates of 97.2 and 60.0 deaths per 100,000 population, respectively (Fig. 2). In $363(4 \%)$ of the 9775 injury death cases, the deceased person is recorded as having been of Aboriginal or Torres Strait Islander origin. This is probably an underestimate, due to incomplete identification of Indigenous status. This complicates reliable reporting of Indigenous injury mortality, which has been made the subject of a special report. ${ }^{52}$ 


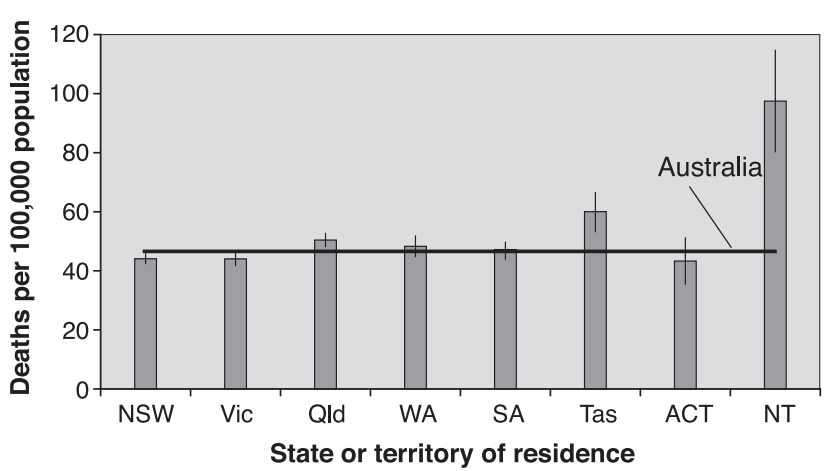

Figure 2 Deaths due to community injury, states and territories of Australia, 2004-2005. ${ }^{12}$

Source: Original source-Figure 2.1.1 Deaths due to community injury by age and sex, Australia 2004-05 from Henley, G. and J. Harrison (2009). Injury deaths, Australia 2004-05, Injury research and statistics series no. 51. AlHW cat. no. INJCAT 127. Canberra: Australian Institute of Health and Welfare; 2009. ${ }^{51}$

Box 1 Characteristics of and problems associated with rural trauma. ${ }^{54,55}$

By comparison with metropolitan areas, in rural trauma there are:

- greater distances travelled

- higher speed of travel-more severe injuries

- poorer road quality

- older age and poorer condition of vehicles

- poor seatbelt compliance

- fatigue and alcohol issues

- delays in discovery times as a result of remoteness $\backslash$ longer transport times

- rural ambulances less well-equipped to deal with multiple trauma

- lower levels of rural practitioner trauma experience (less frequent)

- hospitals less well-equipped to deal with major road crashes and multiple people.

\section{Geography-the tyranny of distance and terrain}

Both Australia and New Zealand have many communities in remote and rural regions; this means that there are large distances between medical facilities, and these may have varying levels of medical care available. The designated trauma centres are situated in the metropolitan areas and therefore many trauma patients are assessed, stabilised, admitted or treated in non-trauma centres. For example in NSW, approximately $25 \%$ of seriously injured patients are initially managed outside a major trauma centre each year. For the major trauma patient, distance from definitive care can have life-threatening consequences and a person suffering major injury in rural Australia is twice more likely to die than if the same accident had occurred in a metropolitan setting. ${ }^{53,54}$ It is for this reason that education for prehospital and rural personnel is so important. Box 1 further illustrates some of the more practical issues around rural trauma.

\section{Suicide}

Suicide became a matter of national public health concern in Australia during the 1990s. Prevention strategies and re-investment in mental health services at both state and federal levels has meant that the male suicide rate in 2002 was the lowest since 1985, and was 20\% lower than in 1997. There were 2191 deaths from suicide registered in 2008. Over three-quarters (78\%) of suicides were males and more than three times as many males as females died from suicide in 2008, continuing the trend of the 10 years since 1999 . $20 \%$ of all deaths in males aged $15-24$ years were due to suicide, and the highest age-specific suicide death rate for males was in the 40 - to 44 -year age group (26.4 per 100,000 population). ${ }^{56}$

In 2008, the most frequent method of suicide was hanging, a method used in half (53\%) of all suicide deaths. Poisoning by drugs was used in $12 \%$ of suicide deaths, followed by poisoning by other methods including by alcohol and motor vehicle exhaust $(11 \%)$. Methods using firearms accounted for $7.8 \%$ of suicide deaths. The remaining suicide deaths included deaths from drowning, jumping from a high place, and other methods. ${ }^{56}$

\section{Transport-related deaths}

Between 1950 and 2005, rates of transport-related deaths in Australia have more than halved. ${ }^{57}$ In the last decade, transportation deaths continued to decline, although at a much slower rate. In 2005, there were 1627 road deaths (rate 8.0 per 100,000 population) and 30,574 people seriously injured (rate 14.8 per 100,000 ). ${ }^{57}$ In 2007-2008 transport accidents accounted for $8.8 \%$ of external-cause separations for public hospitals $(n=61,500)$. The largest proportion of motor vehicles involved in crashes were cars (94\%). ${ }^{16}$

\section{Falls deaths}

In 2007-2008 in Australia, falls were the most commonly reported external cause of admission for both males and females. Queensland, Tasmania, the ACT and the Northern Territory all had falls death rates above the national average, while falls deaths in South Australia were significantly lower than the national average. Although fall rates were concentrated in the older age groups, our understanding of contributing factors is limited by a lack of information about the nature of the falls. In $81 \%$ of deaths related to falls, the cause of the fall was unknown or not documented. Of the known factors contributing to falls-related deaths, tripping, slipping or stumbling on the same level was the most common $(n=75)$, followed by falling from a building or structure $(n=51)$, stairs or steps $(n=39)$ and on or from ladders $(n=25) .{ }^{16}$ While falls prevention is an integral part of injury prevention strategies in Australia, there is little evidence to support injury prevention programs in reducing serious injury, and therefore deaths, related to falls. ${ }^{58}$ 


\section{Work-related fatalities}

Analysis of data derived from workers compensation claims (National Data Set for compensation-based statistics-NDS), notifications under occupational health and safety legislation (Notified Fatalities Collection-NFC) and coronial data (NCIS) identified a total of 453 work-related traumatic injury related fatalities in Australia during 2006-2007. Just over half $(n=237)$ of these resulted from road crashes. This number includes pedestrians hit by vehicles. 295 fatalities occurred as a result of injuries sustained while working $(2.8$ deaths per 100,000 workers). The industries with the highest rates of fatalities are Transport \& Storage (15.7 per 100,000 workers), Agriculture, Forestry \& Fishing (12.6 per 100,000 workers) and Mining (9.6 per 100,000 workers). ${ }^{59}$ Information from separate data sources in Australia (1989-92), New Zealand (1985-98), and the USA (1989-92) has been used to compare the extent and characteristics of motor vehicle traffic incidents on public roads resulting in fatal occupational injuries. Motor vehicle traffic incidents accounted for $31 \%$ (Australia), 22\% (USA) and 16\% (New Zealand) of all work-related deaths during the years covered by the studies. In all three countries, male workers, older workers, and truck drivers were at higher risk, and while rates differed between the three countries, most of the incident characteristics were similar. ${ }^{60}$

\section{Trauma mortality in New Zealand}

In the population of New Zealand as a whole, injury was the fourth leading cause of death and the leading cause of potential years of life lost. Injury killed children at the rate of 16.8 per 100,000 person-years. The victims were predominantly male $(62 \%)$, and $52 \%$ were under 5 years of age. In infancy ( $<1$ year of age), suffocation was the leading cause of injury mortality. From 1 to 14 years of age, motor vehicle incidents were the leading cause of mortality. Motor vehicle incidents, drowning, suffocation and suicide stood out as areas with the greatest potential for reducing child injury mortality. A number of existing prevention strategies show promise (e.g. child restraints); others were inadequately implemented (e.g. swimming pool fencing) or are of unknown efficacy (e.g. government suicide prevention policies). Strategies to reduce infant suffocation and child non-traffic pedestrian deaths remain to be developed and tested. ${ }^{61}$

When injury case fatality rates in the USA were compared with those in New Zealand, using mortality censuses and national hospital discharge censuses, it was found that, overall, unintentional injuries were 1.57 times more likely to be fatal in New Zealand but intentional assault injuries 1.14 times more likely to be fatal in the USA. Firearms were involved in $50 \%$ of assaults in the USA versus $8 \%$ of New Zealand assaults. Cutting/piercing injuries were 1.86 , firearm injuries 1.41 , and motor vehicle injuries 1.44 times more to be likely fatal in New Zealand. Natural/environmental injuries, unintentional poisonings and unintentional suffocations were significantly more likely to be fatal in the USA. Possible reasons for the observed results include differences in geography and proportion of population in rural areas, trauma system differences, road design and vehicle types, seatbelt use, higher use of firearms in assaults in the USA, legislation, policies, and environmental factors. ${ }^{27}$

\section{Trauma morbidity}

For every trauma patient who dies from their injuries, there are nearly six who survive to hospital discharge. For patients with severe injuries (Injury Severity Score (ISS) $>15$ ), the National Trauma Registry Consortium report for Australia and New Zealand shows that almost half of these patients are admitted to intensive care for an average of 7 days. ${ }^{9}$ The average length of hospital stay for this cohort of seriously injured patient varies from 17 to 18 days, depending on whether or not the patient was transferred from another hospital or directly from the scene. ${ }^{9}$ Not all morbidities resulting from trauma are severe or fulminantly disabling. Some result in significant dysfunction, pain, cost and other sequelae, while many minor injuries heal, leaving little or no residual dysfunction. In a significant proportion of moreserious injury, recovery is incomplete, and injury results in a degree of ongoing dysfunction or the onset of secondary conditions (such as osteoarthritis in injured joints). In the Survey of Disability, Ageing and Carers, ${ }^{62}$ one in five people in Australia $(3,958,300$ or $20.0 \%)$ had a reported disability. Of these, $15.2 \%$ reported injury or accident as the underlying cause of their main disabling condition. ${ }^{62}$ The link between major trauma and mental health is recognised, but an area that requires significant further exploration. ${ }^{63}$

\section{Risk factors and prevention}

Whether intended or accidental, most physical injuries can be prevented by identifying their causes and removing them. Understanding some of the risk factors for injury may have predictive value in anticipating patterns of trauma in certain populations and/or informing and evaluating injury prevention strategies. There are a multitude of trauma risk factors, the most common include age, gender, cultural background, alcohol and other drugs, geography, temporal variations and the complex issue of driver distraction.

With the realisation of the incidence and cost of trauma to society, there has been an increasing emphasis on prevention strategies and the establishment of legislative changes to improve road and workplace safety. In the global arena, Australia and New Zealand have been world leaders in introducing legislative changes to improve road and workplace safety. ${ }^{64-67}$ Subsequent improvements in the rates of trauma-related morbidity and mortality have demonstrated the important contribution of legislation in addressing trauma as a public safety.

The perception of trauma as preventable events rather than acts of random unexpectedness is fundamental to the success of any injury prevention program. The Australian National Injury Prevention and Safety Promotion Plan ${ }^{68}$ is a government initiative that universally accepts that injury is preventable and envisions the collaboration of governments, the private sector and communities to ensure that people have the greatest opportunity to live in a safe environment free from the impact of injuries. 


\section{Clinical trauma management implications}

There is ample evidence suggesting insufficient standardisation and hence error in trauma management is a substantial and costly problem in Australia. Errors in trauma management contribute significantly to preventable or potentially preventable morbidity and mortality. ${ }^{57}$ Indeed, most preventable errors occur not because of ignorance or lack of resources, but because the correct therapeutic and diagnostic measures are not performed at the right time, in the right amount or in the right order. ${ }^{69}$ Implementing and maintaining principles of standardising trauma care is vital to optimizing patient recovery and emergency nurses are key to this process.

The Early Management of Severe Trauma (EMST) guidelines were introduced to Australia and New Zealand adapted under license from the Advanced Trauma Life Support (ATLS) guidelines by the Royal College of Surgeons in $1988 .^{70}$ This has ensured a standardised approach to managing trauma for all emergency healthcare clinicians. In addition, the establishment of organised trauma systems, first introduced in Australia in 1992, has improved patient survival. The aim of a trauma system is to facilitate treatment of the injured patient at the right hospital, resulting in optimal care for all trauma patients. Particular emphasis is placed on the development of a trauma system that encompasses pre-hospital care, acute care in the hospital setting, recovery and rehabilitation, in both hospital and home settings, ${ }^{71,72}$ although this has not been evaluated in all Australian or NZ regional health systems. The verification of trauma centres conducted by the Royal Australasian College of Surgeons (RACS) has demonstrated significant improvements in patient care, enhancement of institutional pride, and commitment to care of the injured patient, ${ }^{73}$ although participation by trauma centres remains voluntary.

An organised multidisciplinary team approach to the care of the injured patient is essential to patient outcomes and the successful development of injury management services. ${ }^{74}$ Within trauma centres the multidisciplinary team is developed, led and evaluated by the trauma service. At a minimum, the trauma service should consist of the trauma medical director, trauma coordinator, trauma data manager and administrative support. The trauma service may also include trauma fellows, trauma registrars and case managers. The trauma service coordinates the larger multidisciplinary team tailored to the needs of each patient, and typically consists of various medical and nursing specialties, allied health and rehabilitation clinicians.

The establishment of core trauma nursing roles has been developed to ensure that all injured patients and their families are provided with complete physical and emotional care. The field of trauma encompasses a large variety of nursing specialties, such as injury prevention, emergency, perioperative, intensive care, high-dependency and ward surgical roles through to rehabilitation Currently in Australia, there are two main roles for trauma nurse specialists. The first is the trauma coordinator who, in conjunction with their trauma medical director, oversees trauma care delivery. The second is the trauma case manager, ${ }^{75,76}$ who is supervised by the trauma coordinator and is responsible for the day-to-day clinical coordination of trauma patient care and
Review questions

1. What impact does injury have on the mental health of survivors of traumatic injury?

2. What is the difference in mortality rates between indigenous and other Australians? Is this difference limited to indigenous Australians living in remote communities?

3. What is the incidence of blunt versus penetrating trauma in Australia and New Zealand (expressed in percentages)?

4. List and explain up to 3 demographic risk factors associated with injury

5. List 3 common mechanism of injury responsible for traumatic injury

6. On average, how many years of potential life are lost as a result of fatal injury and how does this compare with cancer and cardiovascular disease?

7. Why is injury prevention important? What prevention strategies have been established in Australia and New Zealand?

8. Describe 3 programs/roles that have improved trauma management in Australia/NZ

informal bedside staff education and patient advocacy. The first trauma nurse practitioner position was introduced in Canberra in 2010. This is an excellent career path for emergency nurses who possess many of the skills for performing the trauma nurse role.

\section{Summary}

The value to clinicians in understanding the context and epidemiology of trauma cannot be overemphasised. An improved understanding of the incidence and prevalence of trauma can empower clinicians of all levels of experience to contribute to improving the trauma system they work in at a local level. It also helps them to reflect on how their respective departments fit into a wider trauma system, and to work towards improving trauma networks and approaches to trauma management at a regional level. An in-depth knowledge of the nature and outcomes of traumatic injury means that trauma clinicians are in a unique position to contribute to injury prevention and interdisciplinary trauma research. Standardising clinical trauma management and ensuring a multidisciplinary approach is maintained holds the potential to reduce error and foster inter-organisational trauma research to improve trauma patient outcomes.

\section{Provenance and conflict of interest}

Kate Curtis is Associate Editor (Trauma) for the Australasian Emergency Nursing Journal but had no role to play in the peer-review or editorial decision-making associated with this paper whatsoever. This paper is an adaptation of Caldwell E, Delprado A, Curtis K, "Overview of Trauma"' in "Emergency and Trauma Care" In Curtis K \& Ramsden C 
(Eds.), Elsevier, Sydney, 2011. It was not commissioned. The authors declared no other conflicts of interest.

\section{Authorship}

The order of authors has been weighted in accordance to author contribution to preparation of manuscript.

\section{Funding}

Nil.

\section{References}

1. World Health Organization global burden of disease study. Geneva: WHO; 2007. Online. Available: via www.globalburden.org.

2. Berndt RM, Berndt $\mathrm{CH}$. The speaking land: myth and story in aboriginal Australia. Vermont: Inner Traditions; 1994.

3. Partington G. The Australian history of Henry Renolds; 1994. Online. Available: www.bennelong.com.au/articles/ pdf/reynolds.pdf.

4. Kirkup J. Foundation lecture. Fracture care of friend and foe during World War I. Aust N Z J Surg 2003;73(6):453-9.

5. Australian Institute of Health and Welfare (AlHW). Australian hospital statistics 2001-2002. Canberra: AlHW; 2003.

6. New Zealand Health Information Service. Selected morbidity data for publicly funded hospitals 2000-2001. Ministry of Health: Wellington; 2004.

7. New Zealand Health Information Service. Mortality and demographic data 2000. Wellington: Ministry of Health; 2004.

8. Moller J, Elkington J. National health priority areas: injury prevention and control. Canberra: Commonwealth Department of Family and Health Services, Australian Institute of Health and Welfare; 1997. p. 6.

9. National Trauma Registry Consortium (Australia and New Zealand) (NTRCANZ). The national trauma registry (Australia and New Zealand) 2003 report. Herston: NTRCANZ; 2005.

10. Delprado A. President's message, December 2010, trauma talk. I. Civil, vol. 12. Melbourne: Australasian Trauma Society; 2010. p. 1-7.

11. Australian Institute of Health and Welfare. Health system expenditure on disease and injury in Australia, 2004-05. Health and Welfare Expenditure Series 36. Cat. no. HSE 87. Canberra, AlHW; 2010.

12. Australian Institute of Health and Welfare. Australian hospital statistics 2007-08. Canberra: AlHW; 2009:1-397. Online. Available: www.aihw.gov.au/publications/hse/hse-7110776/hse-71-10776.pdf.

13. Safe Communities Foundation New Zealand. How big is the injury burden in New Zealand? Online. Available: www.safecommunities.org.nz/Rationale/sc; 22 January 2011.

14. New Zealand Injury Prevention Secretariat. New Zealand injury prevention strategy. Five-year evaluation-final report. Wellington: Accident Compensation Corporation; 2010.

15. Curtis K, Dickson C, Black D, Nau T. The cost and compensability of trauma patients. Aust Health Rev 2009;33(1):84-92.

16. Kreisfeld R, Newson R, Harrison J. Injury death, Australia 2002. Injury research and statistics Series no. 23. Adelaide: Australian Institute of Health and Welfare; 2004.

17. Begg S, Vos T, Barker B, Stevenson C, Stanley L, Lopez A. The burden of disease and injury in Australia 2003. PHE 82. Canberra: Australian Institute of Health and Welfare; 2007.

18. Starr AJ, Smith WR, Frawley WH, Borer DS, Morgan SJ, Reinert $\mathrm{CM}$, et al. Symptoms of post traumatic stress disorder after orthopaedic trauma. J Bone Joint Surg Am 2004;86: 1115-21.

19. Haagsma JA, Polinder S, Toet T, Panneman M, Havelar AH, Bonsel $\mathrm{GJ}$, et al. Beyond the neglect of psychological consequences: post-traumatic stress disorder increases the non-fatal burden of injury by more than 50\%. Inj Prev 2010;17:21-6.

20. Bisson JI, Shepherd JP, Joy D, Probert R, Newcombe RG. Early cognitive-behavioural therapy for post-traumatic stress symptoms after physical injury. Randomised controlled trial. $\mathrm{Br} J$ Psychiatry 2004;184:63-9.

21. Cameron P, Dziukas L, Hadj A, Hooper S. Major trauma in Australia: a regional analysis. J Trauma 1995;39(3):545-52.

22. Stewart J, Allen T. Mechanism of injury. In: Curtis K, Ramsden $\mathrm{C}$, Friendship J, editors. Emergency and trauma nursing. 1st ed. Sydney: Elsevier Science; 2007.

23. Balogh Z. Traumatology in Australia: provision of clinical care and trauma system development. Aust N Z J Surg 2010;80(3):119-21.

24. Hsee L, lan C. Management of low-velocity, non-gunshotwound penetrating abdominal injury: have we moved with the times? N Z Med J 2008;121(1287):26-31. Online. Available: www.nzma.org.nz/journal/121-1287/3400/.

25. Chambers AJ, Lord RS. Management of gunshot wounds at a Sydney teaching hospital. Aust N Z J Surg 2000;70(3):209-15.

26. Wong $K$, Petchell J. Severe trauma caused by stabbing and firearms in metropolitan Sydney: New South Wales, Australia. Aust N Z J Surg 2005;75(4):225-30.

27. Spicer R, Miller T, Langley J, Stephenson S. Comparison of injury case fatality rates in the United States and New Zealand. Inj Prev 2005;11(2):71-6.

28. Australian Bureau of Statistics. Recorded crime-victims, Australia. Report 451 0.0. Canberra; 2009:1-116. Online. Available: $\quad$ www.ausstats.abs.gov.au/Ausstats/subscriber. nsf/0/990A014955F3818DCA2577360017E331/\$File/45100_2009 .pdf.

29. Reed JA, Smith RS, Helmer SD, Carman C. Rates of unemployment and penetrating trauma are correlated. South Med J 2003;96(8):772-4.

30. Thomson I, Muduioa G, Gray A. Vascular trauma in New Zealand: an 11 -year review of NZVASC, the New Zealand Society of Vascular Surgeons' audit database. N Z Med J 2004;117(1201):U1048.

31. Henley G, Harrison JE. Serious injury due to land transport accidents, Australia 2006-07. Injury research and statistics series no. 53. Australian Institute of Health and Welfare Cat. no. INJCAT 129. AlHW; 2009.

32. Henley G, Harrison JE. Serious injury due to transport accidents involving a railway train, Australia 2002-03 to 2006-07. Injury research and statistics series no. 54. Australian Institute of Health and Welfare Cat. no. INJCAT 130. AlHW; 2009.

33. Watson WL, Ozanne-Smith J. The cost of injury to Victoria. Report no. 124. Clayton: Monash University Accident Research Centre; 1997.

34. Flood L, Harrison J. Hospitalised sports injury, Australia 2002-2003. Canberra: Australian Institute of Health and Welfare. AlHW cat. no. INJCAT 79; 2006.

35. Australian Institute of Health and Welfare. AlHW disease expenditure database. Canberra: AlHW; 2004.

36. Cassell E, Clappertone A. Preventing injury in sport and active recreation. Hazard 2002;51:1-18.

37. Olds T, Dollman J, Ridley K, Lowe E. Children and sport: a full report. Canberra: Australian Sports Commission; 2004. p. 17.

38. Hockey R, Knowles M. Sports injuries. Injury Bulletin Queensland Injury Surveillance Unit No. 59; 2000:1-6. Online. Available: www.qisu.org.au/ModCoreFilesUploaded/Bulletin_59131.pdf.

39. Thompson DC, Patterson MQ. Cycle helmets and the prevention of injuries recommendations for competitive sport. Sports Med 1998;25(4):213-9. 
40. Kronisch RL, Pfeiffer RP. Mountain biking injuries: an update. Sports Med 2002;32(8):523-37.

41. Scott D, Hockey R, Barker R, et al. Bicycle injury in Queensland. Injury Bulletin. Queensland Injury Surveillance Unit No. 86; 2005:1-4. Online. Available: www.qisu.org.au/ModCoreFilesUploaded/Bulletin_57133.pdf.

42. Sikic M, Mikocka-Walus AA, Gabbe BJ, McDermott FT, Cameron PA. Bicycling injuries and mortality in Victoria, 2001-2006. MJA 2009;190(7):353-6, www.mja.com.au/ public/issues/190_07_060409/sik11001_fm.html.

43. McRae S. Burns. In: Curtis K, Ramsden C, Friendship J, editors. Emergency and trauma nursing. 1st ed. Sydney: Elsevier Science; 2007.

44. Commonwealth Department of Human Services and Health. Better health outcomes for Australians: national goals, targets and strategies for better health outcomes into the next century. Canberra: AGPS; 1994.

45. Moller J. Estimated cost of injury (\$millions) by fire, flame or burnsAustralia 1995-96; 1998. Online. Available: http://www.nisu. flinders.edu.au/pubs/injcost/burns.html.

46. Barker R, Scott D, Hockey R, et al. Scalds in Queensland Toddlers. Injury Bulletin Queensland Injury Surveillance Unit. No. 89. Online. Available: www.qisu.org.au/ ModCoreFilesUploaded/Bulletin_89100.pdf; 2009.

47. Magill J, Kennedy K. Spinal trauma. In: Curtis K, Ramsden C, Friendship J, editors. Emergency and trauma nursing. 1st ed. Sydney: Elsevier Science; 2007.

48. Cripps RA. Spinal cord injury, Australia 2004-05. Injury Research and Statistics Series No: 29. AlHW cat no. INJCAT 86. Adelaide: AlHW; 2006.

49. Norton L. Spinal cord injury, Australia 2007-08. Canberra: Australian Institute of Health and Welfare; 2010.

50. Canterbury District Health Board. Burwood Spinal Unit admissions statistics 2007-2009. Christchurch: Canterbury DHB; 2010.

51. Henley G, Harrison JE. Injury deaths, Australia 2004-05. Injury Research and Statistics Series no. 51. Cat. no. INJCAT 127. Canberra: Australian Institute of Health and Welfare; 2009.

52. Helps YLM, Cripps R, Harrison JE. Reported injury and mortality of Aboriginal and Torres Strait Islander people in Australia, 1997-2000. Canberra: Australian Institute of Health and Welfare; 2004

53. Australian Bureau of Statistics. A history of road fatalities in Australia. In: Year book Australia.; 2001. Online. Available: www.abs.gov.au/Ausstats/abs@.nsf/dc057c1016e548b4ca256c 470025ff88/9afd4e13d7da281fca2569de0028b40c.

54. Danne PD. Trauma management in Australia and the tyranny of distance. World J Surg 2003;27(4):385-9.

55. Review of trauma and emergency services Victoria. Final report of the Ministerial Taskforce on Trauma and Emergency Services and the department Working Party on Emergency and Trauma Services. Melbourne: Acute Health Division, Victorian Government, Department of Human Services; 1999.

56. Australian Bureau of Statistics. Causes of death, Australia. Canberra: ABS; 2010.

57. Australian Transport Safety Bureau (ATSB). Road crash casualties and rates, Australia, 1925 to 2005. Canberra: ATSB; 2007. Online. Available: www.infrastructure.gov. au/roads/safety/publications/2008/pdf/1925_05_casualties.pdf.

58. National Ageing Research Institute. An analysis of research on preventing falls and falls injury in older people: community, residential care and hospital settings. Canberra: Commonwealth of Australia; 2004.
59. Safe Work Australia. Work-related traumatic injury fatalities Australia 2007-08. Canberra: Commonwealth of Australia; 2010.

60. Driscoll T, Marsh S, McNoe B, Langley J, Stout N, Feyer A-M, et al. Comparison of fatalities from work related motor vehicle traffic incidents in Australia, New Zealand, and the United States. Inj Prev 2005;11(5):294-9.

61. Kypri K, Chalmers DJ, Langley JD, Wright CS. Child injury mortality in New Zealand 1986-1995. J Paediatr Child Health 2000;36(5):431-9.

62. Australian Bureau of Statistics. Survey of disability, ageing and carers (SDAC) publication no. 4430.0. Canberra: Commonwealth of Australia; 2003.

63. O'Donnell ML, Creamer M, Pattison P, Alkin C. Psychiatric morbidity following injury. Am J Psychiatry 2004;161(3): 507-14.

64. Alcohol in Australia: issues and strategies. A background paper to the National Alcohol Strategy: a plan for action 2001 to 2003/04. Commonwealth Department of Health and Aged Care. Commonwealth of Australia; 2001. p. 11.

65. Australian Transport Council. National road safety action plan; 2009/2010. Online. Available: www.atcouncil.gov.au/ documents/atcnrss.aspx.

66. Coneybeare JAC. Evaluation of automobile safety regulations: the case of compulsory seat belt legislation in Australia. Pol Sci 1980;12:27-39.

67. National Occupational Health and Safety Commission. Fatal occupational injuries: how does Australia compare internationally?. Canberra: Department of Communications, Information Technology and the Arts; 2004.

68. National Public Health Partnership. The national injury prevention and safety promotion plan: 2004-2014. Canberra: NPHP; 2004.

69. Chua WC, D’Amours SK, Sugrue M, Caldwell E, Brown K. Performance and consistency of care in admitted trauma patients: our next great opportunity in trauma care? Aust $N$ Z J Surg 2009;79(6):443-8.

70. Carmont MR. The advanced trauma life support course: a history of its development and a review of the related literature. Postgrad Med J 2005;81(952):87-91.

71. Brennan PW, Everest ER, Griggs WM, Slater A, Carter L, Lee $C$, et al. Risk of death among cases attending South Australian major trauma services after severe trauma: the first 4 years of operation of a state trauma system. J Trauma Inj Infect Crit Care 2002;53(2):333-9.

72. Cameron PA, Gabbe BJ, Cooper DJ, Walker T, Judson R, McNeill J. A statewide system of trauma care in Victoria: effect on patient survival. Med J Aust 2008;189(10):546-50.

73. Ehrlich PF, Rockwell S, Kincaid S, Mucha P. American College of Surgeons: committee on trauma verification review: does it really make a difference? J Trauma Inj Infect Crit Care 2002;53(5):811-6.

74. Ursic C, Curtis K, Zou Y, Black D. Improved trauma patient outcomes after implementation of a dedicated trauma admitting service. Injury 2009;40(1):99-103.

75. Sesperez J, Wilson S, Jalaludin B, Seger M, Sugrue M. Trauma case management and clinical pathways: prospective evaluation of their effect on selected patient outcomes in five key trauma conditions. J Trauma 2001;50(4):643-9.

76. Curtis K, Donoghue J. The trauma nurse coordinator in Australia and New Zealand: a progress survey of demographics, role function, and resources. J Trauma Nurs 2008;15(2):34-42. 